Current Opinion in Chemical Engineering

Editor-in-Chief: Kamalesh K. Sirkar

Energy and Environmental engineering / Reaction engineering and catalysis Volume 9

Section Title: Energy and Environmental engineering Section Editors: Rakesh Agrawal and Vasilios I. Manousiouthakis

Submission Deadline: 28 February 2015

Biofuel from fast pyrolysis and catalytic hydrodeoxygenation.

Corresponding Author and title:

Douglas C. Elliott

Pacific Northwest National Laboratory

P.O. Box 999, MSIN P8-60

Richland, Washington, USA

dougc.elliott@pnnl.gov

tel +1-509-375-2248, fax +1-509-372-4732 


\title{
Biofuel from Fast Pyrolysis and Catalytic Hydrodeoxygenation.
}

\author{
Douglas C. Elliott
}

\begin{abstract}
This review addresses recent developments in biomass fast pyrolysis bio-oil upgrading by catalytic hydrotreating. The research in the field has expanded dramatically in the past few years with numerous new research groups entering the field while existing efforts from others grow. The issues revolve around the catalyst formulation and operating conditions. Much work in batch reactor tests with precious metal catalysts needs further validation to verify long-term operability in continuous flow systems. The effect of the low level of sulfur in bio-oil needs more study to be better understood. Utilization of the upgraded bio-oil for feedstock to finished fuels is still in an early stage of understanding.
\end{abstract}

\section{INTRODUCTION}

Process research and development for biomass fast pyrolysis and catalytic hydrotreating (HT) of the bio-oil product has been ongoing for over 30 years. The level of effort has waxed and waned over the years essentially with the rise and fall of the price of petroleum. With the rise of the petroleum price since 2007, there has been another expansion in the research effort. 'This review covers the past few years of R\&D outcomes resulting from this higher level of activity. An important review of hydrodeoxygenation (HDO) processing includes a large portion describing developments in fast pyrolysis bio-oil upgrading." Another review written more specifically to bio-oil upgrading to fuels concludes that $\mathrm{HT}$ is the preferred route compared to non-hydrogenative catalytic cracking, which has also received extensive R\&D.iii Finally, the review from PNNL draws together the relevant publications from 2008 to 2013 to provide the basis for the multi-step-temperature HT required to upgrade fast pyrolysis bio-oil. ${ }^{\text {iv }}$ This review builds on that one and describes the most compelling research on the subject in the last 2-4 years.

Fast Pyrolysis

The specification of fast pyrolysis bio-oil is an important consideration. It has been well-defined in the CAS \# 1207435-39-9.

"Liquid condensate recovered by thermal treatment of lignocellulosic biomass at short hot vapor residence time (typically less than about 5 seconds) typically at between $450-600{ }^{\circ} \mathrm{C}$, at near atmospheric pressure or below, in the absence of oxygen, and using small (typically less than $5 \mathrm{~mm}$ ) dry (typically less than $10 \%$ water) biomass particles.

A number of engineered systems have been used to effect high heat transfer into the biomass particle and quick quenching of the vapor product, usually after removal of solid byproduct "char", to 
Other types of biomass pyrolysis oil produced under less specified conditions, typically longer residence time or lower temperature, will have a different chemical composition and will therefore have different chemical and physical properties. The HT processing described in this review has been developed to address the properties of fast pyrolysis bio-oil.

Catalytic Hydrotreating of Bio-oil

$\mathrm{HT}$ can be effective in removing heteroatoms, principally oxygen, and in producing useful hydrocarbon liquids. Thermally staged treatment is required due to the thermally reactive nature of biooil. This is a very important difference from HT of petroleum oils, which contain much lower heteroatom contents and are inherently more thermally stable as a result. Bio-oil cannot be directly processed in a petroleum refinery, but consideration has been given to how its blending into various petroleum streams might be implemented. ${ }^{\vee}$ A recent comparison was made of the competitive chemical mechanisms occurring in the hydrotreating environment, namely thermal polymerization versus catalytic hydrogenation. ${ }^{\text {vi }}$ Two-stage HT has been the accepted practice for the last 25 years, but a new variation involving the addition of solvent in the low-temperature first step to overcome coke formation has now been reported. vii However, the authors acknowledge the limited use of the data presented as the added solvent was not separated, so the product was contaminated and recovery for reuse was not demonstrated.

3-stage HT has been demonstrated effectively for extended operation with bio-oil. The first goal of $700 \mathrm{~h}$ of operation with a single catalyst load was achieved in 2012, ${ }^{\text {viii }}$ and during 2013 this effort was extended to $1440 \mathrm{~h}$ of time on stream. ${ }^{\text {ix }}$ A recent patent application extends this concept to multi-port injection of hydrogen at continually increasing temperature in order to control the exothermic reaction through controlled addition of the hydrogen reactant. ${ }^{x}$ An alternative low-temperature pretreatment step under development involves oxidation of the carbonyls in bio-oil to acids prior to more conventional hydrotreatment. ${ }^{\text {xi } x i i}$

Research continues to explore the HT of bio-oil produced from new biomass feedstocks. Researchers at Pacific Northwest National Laboratory investigated the use of the phase separated heavy (lignin-rich) fraction from bio-oil for production of liquid fuels and low-sulfur coke, ${ }^{\text {xiii }}$ bio-oil produced from mountain pine beetle killed trees and hog fuel, ${ }^{\text {xiv }}$ and pine bio-oil and the extractant-rich top phase from softwood pyrolysis. ${ }^{\mathrm{xv}}$ Another effort by the Eastern Regional Research Center of the USDA 

produced from pennycress seed presscake. ${ }^{\text {xvi }}$

Effect of Sulfur

Bio-oil will contain more or less $S$ depending on the initial biomass feedstock. The amount of $S$ can vary from less than $50 \mathrm{ppm}$, as for clean white wood, to some tenths of percent for biomasses containing higher levels of protein. The use of precious metal catalysts is limited by the amount of $S$ in the bio-oil as the metal catalysts would be readily poisoned. None the less, there is still significant interest in the use of precious metal catalysts for bio-oil HT. ${ }^{\text {xvii }}$ Most of the studies on precious metal catalysts have been done in short batch reactor tests or limited time on stream tests.

A group in China has evaluated the use of NiMo catalyst in the non-sulfided form. Building on their earlier effort, they identified optimum formulations and reduction conditions for catalysts that have very little activity $\left(33 \%\right.$ reduction of acetic acid at $200^{\circ} \mathrm{C}$, 30 bar, but very little change in bio-oil). ${ }^{\text {xviii }}$ The group further examined a series of Ru and bimetallic catalysts at the same low severity conditions. CoRu was identified as the most active catalyst for acetic acid conversion (31\%). When similarly applied on biooil there was little effect, but the step was proposed as a pretreatment to stabilize the bio-oil by reacting the acids to esters. ${ }^{\text {xix }}$ Surprisingly good $\mathrm{HDO}$ results with unsulfided $\mathrm{CoMo} / \mathrm{\gamma}-\mathrm{Al}_{2} \mathrm{O}_{3}$ catalyst were reported in a comparative study wherein FeW/Si-Al, $\mathrm{FeCr}$ and mixed $\mathrm{Ru} / \mathrm{V}-\mathrm{Al}_{2} \mathrm{O}_{3}$ and $\mathrm{Ni} / \mathrm{SiAl}$ catalysts were also tested. ${ }^{\mathrm{xx}}$ While only moderate activity for reduction of acid and increase in HHV was found with the FeW and Fe-Cr catalysts, both the CoMo and the Ru-Ni were very active resulting in nearly complete HDO.

\section{Precious Metal Catalysts}

Much of the recent research has used precious metals on carbon supports. Pd has received wide-spread interest. Li's group at Curtin University in Australia, using a 5\% Pd/C catalyst, has an important series of publications reporting the transformation of light species during hydrotreatment, ${ }^{\mathrm{xxi}}$ the importance of holdup of heavy species in a packed-bed catalytic reactor, ${ }^{\text {xxii }}$ and the changes in aromatic structures. ${ }^{\text {xiii }}$ However, there is no recognition or data provided relative to $S$ poisoning of the catalyst and no indication of catalyst deactivation in these short tests, so the results may not be useful for an actual bio-oil HT process. A separate study from Korea reports only partial deoxygenation (55-60\%) at $350^{\circ} \mathrm{C}$ and $60 \mathrm{~min}$ in a batch reactor using a $5 \% \mathrm{Pd} / \mathrm{C}$ catalyst. ${ }^{\text {xiv }}$ A recent batch study shows that the reactive carbonyl components can be hydrogenated even at room temperature over a $10 \% \mathrm{Pd} / \mathrm{C}$ catalyst given sufficient time (16 h). (unpublished Rover MR, et al. 2015.), but again there is no consideration of $\mathrm{S}$ poisoning.

A modeling effort with Pt and Ni catalysts for phenol hydrogenation in liquid aqueous medium has been recently published. ${ }^{x \times v}$ Applicable to bio-oil $\mathrm{HT}$, the authors concluded that hydrogenation in the 

phase reaction. This effort correlates well with Lercher's earlier study of Pd/C catalyzed hydrogenation of various phenolics in aqueous phase, which found that the saturated cyclic ketone was the important intermediate. ${ }^{\text {xxi }}$

Ru continues to be tested for bio-oil HT. A two-stage reactor with both beds filled with Ru/C catalysts was used as the source for analysis by electrospray ionization Fourier transform ion cyclotron resonance mass spectrometry (ESI FT-ICR MS) of bio-oil and HT bio-oil. ${ }^{x x v i i}$ The space velocity used was very high (3.3) so the extent of deoxygenation was not great ( 25 to $55 \%$ ). There was limited evidence of saturation, but phenolics were stable. The time on stream was not given and there is no discussion of catalyst deactivation.

Recent attempts to improve the HT with precious metal catalysts have involved added polyethylene glycol as a solvent/dispersant. Switchgrass fast pyrolysis bio-oil was treated at low severity conditions (200-280 ${ }^{\circ} \mathrm{C}$ and 20-70 bar) using either Ru or Rh. ${ }^{\text {xxvii }}$ Although there is significant analysis of the products and mechanisms, showing mostly saturation and limited deoxygenation, there is no recognition of the sulfur poisoning issue. In these short batch tests poisoning of the catalyst by the sulfur in the bio-oil (reportedly in the range of 800 ppm for switchgrass ${ }^{x x i x}$ ) might not be an issue, but it would be deadly in long-term operation. Another study of $\mathrm{Pt}$, Ru and Pd catalysts using bio-oil derived from switchgrass, eucalyptus, and equine manure at somewhat more severe conditions $\left(320^{\circ} \mathrm{C}, 140 \mathrm{bar}\right)$ provides similar results, but again no analysis of $S$ in the bio-oil was reported. ${ }^{x \times x}$ The $S$ level would be expected to be as high in these feedstocks or even higher in the manure derived bio-oil.

Innovative Use of Sulfided Catalysts

A semi-batch reactor was used over a range of temperature settings to evaluate sulfided NiMo versus precious metal catalysts. ${ }^{x \times i}$ In these short tests the $S$ content was not considered, but catalyst analysis following the tests did show a significant effect of metal sintering for the precious metals on $\mathrm{C}$ supports, which would be expected to lead to catalyst deactivation. The authors concluded that the sulfided catalyst provided the desired reduction in acids, unlike the precious metals.

Hydrodenitrogenation of a sewage sludge fast pyrolysis oil was studied using a sulfided NiMo on phosphated alumina. When diluted at $10 \%$ in nonpolar solvent, $\mathrm{N}$ was reduced below the level of detection, while in polar solvent the activity was much more limited. ${ }^{\text {xxii }}$

\section{Alternatives to Conventional Catalyst Supports}

Most of the research on bio-oil HT has used conventional promoted Mo catalysts formulated on a high-surface area alumina support, typically $v$-alumina. This form of alumina is not stable in hydrothermal conditions and earlier work has suggested it would not be stable for bio-oil HT. In addition, the alumina support has been reported to catalyze coke formation when processing phenolics. The 
mechanism for phenate binding to the catalyst has been studied recently and confirmed that the binding occurred not on the Mo sites but directly on the alumina, thus indirectly poisoning the catalyst sites by reducing the accessibility. This effect occurs for all but the most basic phenols tested, 2(4)-ethyl phenol and guaiacol. ${ }^{\text {xxiii }}$

An innovative bimetallic catalyst composed of $\mathrm{Ni}$ and $\mathrm{Cu}$ was based initially on alumina, but it was found to be leached during the reaction and coke deposition was noted. ${ }^{\text {xxiv }}$ Subsequent work compared a range of support materials including zirconia, titania, silica, $\mathrm{CeO}_{2}-\mathrm{ZrO}_{2}, \mathrm{C}$, and sibunite. Titania (anatase) was found to produce the most active catalyst, while the zirconia support appeared to be least affected in the reaction environment, although it did change from amorphous to the monoclinic/cubic crystalline form. ${ }^{x x y}$ However, these metal catalysts remain subject to $S$ poisoning and the short term nature of the tests did not allow for steady state stability determinations.

$\mathrm{Ni}$ metal catalysts were synthesized on mixed oxides and tested with guaiacol model compound and a whole bio-oil feedstock. Of the oxides tested ( $\mathrm{Al}-\mathrm{Si}, \mathrm{Al}-\mathrm{Ti}, \mathrm{Ti}-\mathrm{Si}, \mathrm{Ti}-\mathrm{Zr}$ ) the titania-zirconia support was found to give the most active catalyst for guaiacol HDO. In tests with bio-oil, it was also found to be active in a short batch test, but coking of the catalyst was visible to the eye. ${ }^{\text {xxxi }}$

Further work with zirconia as the catalyst support for mixed precious metals was also reported. The authors concluded that, of the metals tested (Rh, Pd, Pt, RhPt, RhPd, PdPt) Rh and Pd alone were the most useful formulations. Tests for extended time showed deactivation of the catalyst. Concern for $\mathrm{S}$ poisoning was suggested, but not investigated. Coke formation was found $(2.7 \% \mathrm{C})$ but could be removed by controlled oxidation below $400^{\circ} \mathrm{C}$. In a comparative test with sulfided CoMo on alumina it was determined that the catalyst lost $S$ during the reaction despite the $100 \mathrm{ppm}$ of $\mathrm{S}$ in the feed. $\mathrm{S}$ tolerance of the precious metals was not evaluated. Further, the activity of the CoMoS catalyst was significantly lower than the precious metals based on metal weight, though twice as high based on catalyst bed volume, due to the low metal loading $(0.5 \%)$ for the precious metals. ${ }^{\text {xxvii }}$

Specialty carbons have also been tested as catalyst supports. In addition to the sibunite mentioned earlier, ${ }^{x \times \mathrm{x}} \mathrm{Ni}$ or NiMo on carbon nanotubes has been evaluated in hydrotreating model compounds and bio-oil at low temperature $\left(<250{ }^{\circ} \mathrm{C}\right)$. A $10 \% \mathrm{Ni}$ and $10 \%$ Mo formulation was determined to be most effective. The activity of the catalyst was low at the low temperature, and the short batch tests did not allow for stability determination. ${ }^{\text {xxviii }} \mathrm{C}$ nanofibers grown on an Inconel monolith were also tested for supporting bimetallic Pt-Sn catalysts. The bimetallic form was found to be more active and stable than either metal alone in model compound tests, but deactivation over the $3 \mathrm{~h}$ experiment was a concern. ${ }^{\mathrm{xx} x \mathrm{x}}$

A bi-phasic homogeneous catalyst has been tested for bio-oil HT. The report indicates that the Ru-containing Shvo catalyst has activity even at low severity conditions $\left(145^{\circ} \mathrm{C}, 10 \mathrm{bar}, 1 \mathrm{~h}\right)$ in the presence of acid for hydrogenation of double bonds without affecting aromatic rings resulting in the almost complete conversion of ketones and aldehydes. However, recovery of the homogeneous catalyst, which was soluble in bio-oil, remained a major problem. ${ }^{\mathrm{xl}}$ 


\section{Effect of Minerals}

Recent investigations have addressed the presence of trace elements in the biomass feedstock and their fate through fast pyrolysis processing and HT of the bio-oil. Hot vapor filtration has been

applied to reduce the mineral content in bio-oil, and the resulting effect in HT has been evaluated. ${ }^{\text {xxix }}$ The HT of the hot-vapor-filtered bio-oils, which were low in mineral content even unfiltered, showed minimal differences in catalyst activity over a 5 day test in a continuous-flow, fixed-bed catalytic reactor system. The elemental analysis of the used catalyst beds for filtered bio-oil showed evidence of less deposition compared to the catalysts used with non-filtered bio-oils from switchgrass, which was higher in mineral content. When biomasses with higher mineral content, like forest residues, were pyrolyzed and hydrotreated, it was confirmed that inorganic-laden biomass yields less bio-oil, but the resultant bio-oil can be upgraded to hydrocarbons at a higher yield than bio-oil from clean wood. Thus, the final hydrocarbon yield from clean or residue biomass pyrolysis/upgrading was unexpectedly similar. xiv $^{\text {. }}$

\section{Quality of Products}

Analysis of the products of bio-oil HT has progressed beyond the more common elemental composition, component analysis by GCMS, and simple fuel properties such as density, viscosity and acid content. HT products with a range of residual oxygen content from 0.4 to $8 \%$ were distilled and the fractions analyzed by a suite of fuel and advanced chemical tests. ${ }^{x l i}$ A separate study provided the important information on the properties that are relevant to bio-oil HT and utilization of the products. ${ }^{\text {xli }}$

\section{Utilization of Hydrotreated Bio-oil}

Mild hydrotreating has been applied to bio-oil in an attempt to sufficiently stabilize the bio-oil so that it can be processed in conventional petroleum processing systems. In one study, bio-oil was fractionated by water addition to force phase separation and then hydrotreated to residual oxygen levels varying from 14 to $27 \%$ (dry wt.). These products were produced using a precious metal catalyst and as a result were highly saturated and the carbonyls removed. The products produced could be successfully processed when diluted to $20 \%$ by Long Residue in a catalytic cracker. When coprocessed at $30 \%$ with straight run gas oil in a HDS unit, competition between HDS and HDO reactions was observed, but without permanent catalyst deactivation. The result of coprocessing was similar to processing only fossil oil and independent of the origin of the HDO bio-oil. ${ }^{\text {xliii }}$ In a separate study, the level of oxygen removal was higher yet the products were still often immiscible with hexane or toluene. ${ }^{\text {xliv }}$ The catalyst in this case was a sulfided NiMo, which resulted in a lower level of residual oxygen but also a lower $\mathrm{H}$ to $\mathrm{C}$ ratio, suggesting less saturation.

In an economic assessment of bio-oil HT, it was concluded that it is likely that some bio-oil components, upgraded to some degree, will be processed in existing refinery facilities and blended with petroleum-derived components to produce "drop-in" gasoline and diesel fuels. Large savings are 
possible if more of the bio-oil upgrading can be done in existing refining facilities, but physical and economic feasibility is not known at this point, in part due to a lack of understanding of bio-oil composition at various stages of deoxygenation. ${ }^{x / v}$ The authors identified the most promising areas for economic improvement, which needed future research: 1) Identification of a stable upgrading catalyst, 2) Definition of the maximum level of oxygen that can be tolerated by the existing refining infrastructure, and 3) Improved oxygen removal during the pyrolysis step. ${ }^{\text {xlvi }}$

\section{CONCLUSION}

The technology for producing infrastructure compatible fuels from biomass using fast pyrolysis and catalytic hydrotreating (HT) is in an early stage of development. The use of bio-oil produced at fast pyrolysis conditions needs to be confirmed when performing HT research. The question of the use of sulfided or unsulfided metal catalysts for bio-oil HT needs to be clarified in light of the variable amount of $S$ in bio-oil products from various biomass feedstocks. New catalytic formulations and methods are under development and being tested. The use of batch reactor systems has limited utility for process development, except in the earliest stages, and R\&D based on continuous-flow reactor systems needs to be expanded.

\section{ACKNOWLEDGEMENTS}

This review was supported by the U.S. Department of Energy (DOE) under Contract DE-AC0576RL01830 at the Pacific Northwest National Laboratory. Funding was provided by the DOE Bioenergy Technologies Office.

\section{REFERENCES}

\footnotetext{
'Elliott DC: Transportation fuels from biomass via fast pyrolysis and hydroprocessing. WIREs Energy Environ. 2013. doi: 10.1002/wene.74.

*This overview provides a useful introduction and review of the subject.

ii Furimsky E:Hydroprocessing challenges in biofuels production. Catalysis Today 2013, 217:13-56.

*This review builds on earlier reviews by Furimsky of catalytic hydrodeoxygenation - Applied Catalysis 2000, 199: 147-190 and Catal. Rev.-Sci. Eng. 1983, 25: 421-458.

iii Mortensen PM, Grunwaldt J-D, Jensen PA, Knudsen KG, Jensen AD: A review of catalytic upgrading of bio-oil to engine fuels. Applied Catalysis A: General 2011, 407: 1-19.

iv Zacher AH, Olarte MV, Santosa DM, Elliott DC, Jones SB: A review and perspective of recent bio-oil hydrotreating research. Green Chemistry 2013 DOI: 10.1039/c3gc41382a.

*This review best describes the developments in multi-step hydrotreating required for fast pyrolysis bio-oil, which has been developed at the Pacific Northwest National Laboratory over the last three decades.

'Talmadge MS, Baldwin RM, Biddy MJ, McCormick RL, Beckham GT, Ferguson GA, Czernik S, Magrini-Bair KA, Foust TD, Metelski PD, Hetrick C, Nimlos MR: A perspective on oxygenated species in the refinery integration of pyrolysis oil. Green Chemistry 2013 DOI: 10.1039/c3gc41951g.
} 
${ }^{v i}$ Mercader FdM, Koehorst PJJ, Heeres HJ, Keersten SRA, Hogendoorn JA: Competition between hydrotreating and polymerization reactions during pyrolysis oil hydrodeoxygenation. AlChE Jour. 2011 57(11): 3160-3170.

${ }^{\text {vii }}$ Xu X., Zhang C, Liu Y, Zhai Y, Zhang R: Two-step catalytic hydrodeoxygenation of fast pyrolysis oil to hydrocarbon liquid fuels. Chemosphere 2013 93:652-660.

viii Olarte MV, Elliott DC, Neuenschwander GG, Rotness L, Burton SD, Schwenzer B, Padmaperuma A, Zacher AH: Towards long-term fast pyrolysis oil catalytic upgrading. Prepr. Pap.-Am. Chem. Soc., Div. Energy Fuels 2013, 58(2): 230-231.

ix Jones SB, Snowden-Swan LJ, Meyer PA, Zacher AH, Olarte MV, Drennan C: Fast Pyrolysis and Hydrotreating: 2013 State of Technology R\&D and Projections to 2017. PNNL-23294, March 2014. Pacific Northwest National Laboratory, Richland, Washington, USA.

*This report provides the details of the latest process development from PNNL for bio-oil HT.

${ }^{x}$ Mayeur V, Preau A: Process for hydrodeoxygenation and process for upgrading of pyrolysis oil resulting from biomass, which are capable of operating continuously. U.S. patent application 2013/0255138 A1, Oct. 3, 2013.

*This concept is forward looking and incorporates concepts currently used in petroleum hydrocracking,

${ }^{x i}$ Tanneru SK, Steele PH: Pretreating bio-oil to increase yield and reduce char during hydrodeoxygenation to produce hydrocarbons. Fuel 2014 133:326-331.

xii Steele PH, Tanneru SK, Gajjela SK: Composition and methods for improved fuel production. US patent application 2013/0291431 A1.

xiii Elliott DC, Neuenschwander GG, Hart TR: Hydroprocessing bio-oil and products separation for coke production. ACS Sust. Chem. Eng. 2013 1(4) 389-392.

xiv Zacher AH, Elliott DC, Olarte MV, Santosa DM, Preto F, lisa K: Pyrolysis of woody residue feedstocks: Upgrading of bio-oils from mountain-pine-beetle-killed trees and hog fuel. Energy Fuels 2014 28:7510-7516.

${ }^{x v}$ Elliott DC, Hart TR, Neuenschwander GG, Rotness LJ, Olarte MV, Zacher AH, Solantausta Y: Catalytic hydroprocessing of fast pyrolysis bio-oil from pine sawdust. Energy Fuels 2012 26:3891-3896.

xvi Mullen CA, Boateng AA, Reichenbach SE: Hydrotreating of fast pyrolysis oils from protein-rich pennycress seed presscake. Fuel 2013 111:797-804.

xvii Wang $\mathrm{H}$, Male J, Wang Y: Recent advances in hydrotreating of pyrolysis bio-oil and its oxygen-containing model compounds. ACS Catalysis 2013 3: 1047-1070.

xviii Xu Y, Wang T, Ma L, Zhang Q, Liang W: Upgrading of the liquid fuel from fast pyrolysis of biomass over MoNi/ $\mathbf{Y}$ $\mathrm{Al}_{2} \mathrm{O}_{3}$ catalysts. Appl. Energy 2010 87:2886-2891.

${ }^{\text {xix }}$ Xu Y, Wang T, Ma L, Chen G: Upgrading of fast pyrolysis liquid fuel from biomass over $\mathrm{Ru} / \mathrm{V}-\mathrm{Al}_{2} \mathrm{O}_{3}$ catalyst. Energy Convers. Management 2012 55:172-177.

${ }^{\mathrm{xx}}$ Parapati DR, Guda VK, Penmetsa VK, Steele PH, Tanneru SK: Single stage hydroprocessing of pyrolysis oil in a continuous packed-bed reactor. Environ. Prog. Sust. Energy 2014 33(3):726-731.

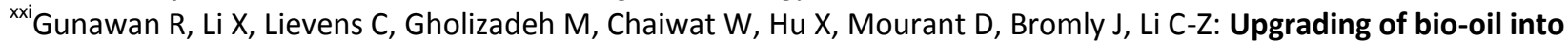
advanced biofuels and chemicals. Part I. Transformation of GC-detectable light species during the hydrotreatment of bio-oil using Pd/C catalyst. Fuel 2013 111:709-717.

xxii Chaiwat W, Gunawan R, Gholizadeh M, Li X, Lievens C, Hu X, Wang Y, Mourant D, Rossiter A, Bromly J, Li C-Z: Upgrading of bio-oil into advanced biofuels and chemicals. Part II. Importance of holdup of heavy species during the hydrotreatment of bio-oil in a continuous packed-bed catalytic reactor. Fuel 2013 112:302-310.

*This study recognizes the importance of steady state operation in continuous-flow reactors and the difficulties in achieving such with the mixed phase of hydrogen, water, bio-oil feed and deoxygenated products, which include a wide range of molecular weight and polarity.

xxiii Li X, Gunawan R, Wang Y, Chaiwat W, Hu X, Gholizadeh M, Mourant D, Bromly J, Li C-Z: Upgrading of bio-oil into advanced biofuels and chemicals. Part III. Changes in aromatic structure and coke formation propensity during the catalytic hydrotreatment of a fast pyrolysis bio-oil with Pd/C catalyst. Fuel 2014 116:642-649.

${ }^{x x i v}$ Kim T-S, Oh S, Kim J-K, Choi I-G, Choi JW: Study on the hydrodeoxygenation upgrading of crude bio-oil produced from woody biomass by fast pyrolysis. Energy 2014 68:437-443.

${ }^{x x v}$ Yoon Y, Rousseau R, Weber RS, Mei D, Lercher JA: First-principles study of phenol hydrogenation on Pt and Ni catalysts in aqueous phase. Jour. Amer. Chem. Soc. 2014 136:10287-10298. 

alkanes. Angew. Chem. Int. Ed. 2009 48:3987-3990.

xxvii Bi Y, Wang G, Shi Q, Xu C, Gao J: Compositional changes during hydrodeoxygenation of biomass pyrolysis oil. Energy Fuels 2014 28:2571-2580.

xxviii Nan W, Krishna CR, Kim T-J, Wang L, Mahajan D: Catalytic upgrading of switchgrass-derived pyrolysis oil using supported ruthenium and rhodium catalysts. Energy Fuels 2014 28:4588-4595.

${ }^{\text {xxix }}$ Elliott DC, Wang H, French R, Deutch S, lisa K: Hydrocarbon liquid production from biomass via hot-vapor filtered fast pyrolysis and catalytic hydroprocessing of the bio-oil. Energy Fuels 2014 28: 5909-5917,

${ }^{x x x}$ Elkasabi Y, Mullen CA, Pighinelli ALMT, Boateng AA: Hydrodeoxygenation of fast-pyrolysis bio-oils from various feedstocks using carbon-supported catalysts. Fuel Proc. Technol. 2014 123:11-18.

${ }^{x x x i}$ French RJ, Stunkel J, Black S, Myers M, Yung MM, lisa K: Evaluate impact of catalyst type on oil yield and hydrogen consumption from mild hydrotreating. Energy Fuels 2014 28:3086-3095.

xxxii Izhar S, Uehara S, Yoshida N, Yamamoto Y, Morioka T, Nagai M: Hydrodenitrogenation of fast pyrolysis bio-oil derived from sewage sludge on NiMo/Al2O3 sulfide catalyst. Fuel Proc. Technol. 2012 101:10-15.

xxxiii Popov A, Kondratieva E, Mariey L, Goupil JM, Fallah JE, Gilson J-P, Travert A, Maugé F: Bio-oil hydrodeoxygenation: Adsorption of phenolic compounds on sulfided (Co)Mo catalysts. Jour. Catal. 2013 297:176186.

xxxiv Ardiyanti AR, Khromova SA, Venderbosch RH, Yakovlev VA, Heeres HJ: Catalytic hydrotreatment of fast pyrolysis oil using non-sulfided bimetallic $\mathrm{Ni}-\mathrm{Cu}$ catalysts on a $\delta-\mathrm{Al}_{2} \mathrm{O}_{3}$ support. Appl. Catal. B: Environ. 2012 117118: 105-117.

${ }^{x x x v}$ Ardiyanti AR, Khromova SA, Venderbosch RH, Yakovlev VA, Melian-Cabrera IV, Heeres HJ: Catalytic hydrotreatment of fast pyrolysis oil using bimetallic Ni-Cu catalysts on various supports. Appl. Catal.A General 2012 449: 121-130

xxxvi Zhang X, Long J, Kong W, Zhang Q, Chen L, Wang T, Ma L, Li Y: Catalytic upgrading of bio-oil over Ni-based catalysts supported on mixed oxides. Energy Fuels 2014 28:2562-2570.

xxxvii Ardiyanti AR, Gutierrez A, Honkela ML, Krause AOI,, Heeres HJ: Hydrotreatment of wood-based pyrolysis oil using zirconia-supported mono- and bimetallic (Pt, Pd, Rh) catalysts. Appl. Catal.A General 2011 407: 56-66. *This paper provides important information on zirconia supported catalysts and the effect of sulfur. xxxviii Zhou M, Tian L, Niu L, Li C, Xiao G, Xiao R: Upgrading of liquid fuel from fast pyrolysis of biomass over modified Ni/CNT catalysts. Fuel Proc. Technol. 2014 126:12-18.

xxxix González-Borja MÁ, Resasco DE: Anisole and guaiacol hydrodeoxygenation over monolithic Pt-Sn catalysts. Energy Fuels 2011 25:4155-4162.

${ }^{x l}$ Busetto L, Fabbri D, Mazzoni R, Salmi M, Torri C, Zanotti V: Application of the Shvo catalyst in homogeneous hydrogenation of bio-oil obtained from pyrolysis of white poplar: New mild upgrading conditions. Fuel 2011 90:1197-1207.

${ }^{x l i}$ Christensen ED, Chupka G, Luecke J, Smurthwaite T, Alleman TL, lisa K, Franz JA, Elliott DC, McCormick RL: Analysis of oxygenated compounds in hydrotreated biomass fast pyrolysis oil distillate fractions. Energy Fuels 2011 25:5462-5471.

*This reference provides the most detailed chemical analysis of hydrotreated bio-oil fractions.

xlii Oasmaa A, Kuoppala E, Elliott DC: Development of the basis for an analytical protocol for feeds and products of bio-oil hydrotreatment. Energy Fuels 2012 26:2454-2460;

xliii Mercader FdM, Groeneveld MJ, Kersten SRA, Geantet, C, Toussaint G, Way NWJ, Schaverin CJ, Hogendoorn KJA: Hydrodeoxygenation of pyrolysis oil fractions: Process understanding and qulity assessment through coprocessing in refinery units. Energy Environ. Sci. 2011 4:985-997.

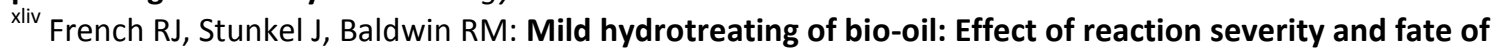
oxygenated species. Energy Fuels 2011 25:3266-3274.

${ }^{x l v}$ Arbogast S, Bellman D, Paynter JD, Wykowski J: Advanced biofuels from pyrolysis oil: The impact of economies of scale and use of existing logistic and processing capabilities. Fuel Proc. Technol. 2012 104:121-127

${ }^{x l v i}$ Arbogast S, Bellman D, Paynter JD, Wykowski J: Advanced biofuels from pyrolysis oil...Opportunities for cost reduction. Fuel Proc. Technol. 2013106 518-525. 